\title{
Bumbometer digital crowd game: collaboration through competition in entertainment events
}

\author{
Gustavo Martins (1) [ Universidade Federal do Amazonas $\mid$ gfm@icomp.ufam.edu.br ] \\ Genildo Gomes (D) [ Universidade Federal do Amazonas $\mid$ genildo.gomes@icomp.ufam.edu.br ] \\ Júlia Luiza Conceição iD [ Universidade Federal do Amazonas |jlslc@icomp.ufam.edu.br ] \\ Leonardo Marques (D) [ Universidade Federal do Amazonas | lcm@icomp.ufam.edu.br ] \\ Dan da Silva (D) [ Universidade Federal do Amazonas $\mid$ dfs@icomp.ufam.edu.br ] \\ Thais Castro (D) [ Universidade Federal do Amazonas | thais@icomp.ufam.edu.br ] \\ Bruno Gadelha (D) [ Universidade Federal do Amazonas | bruno@icomp.ufam.edu.br ] \\ Rosiane de Freitas (D) [ Universidade Federal do Amazonas | rosiane@icomp.ufam.edu.br ]
}

\begin{abstract}
The use of mobile devices, especially smartphones, is widespread across all social strata and age groups, helping to ensure faster access from anywhere, data collection, and more regular and frequent control to aid urban, environmental, and social management. In this scenario, the entertainment industry has benefited from this powerful individual technological resource in cultural and sporting events. In this way, this work presents a proposal for interaction and engagement in entertainment events in a more prosperous and more technological way, through the development of a collaborative and competitive mobile-web crowd game, intended for enhancing interaction between the crowd and as a unified group, whether physically co-located or online. The application, called Bumbometer, uses motion sensors during an interactive dynamic with the crowd applying concepts from Mobile Crowd Sensing and User eXperience. We conducted two experimental studies to evaluate the proposed technology, the first in a real scenario of a folk cultural festival and the second in a controlled environment, simulating an event considering a scenario in which users were geographically distant. The results indicate that people feel immersed and engaged during the interaction through the proposed game, which reinforces the statement that the game meets an increasingly growing need to use technologies to ensure more significant interaction and audience immersion at crowd entertainment events, a creative and far-reaching form.
\end{abstract}

Keywords: crowd computing, crowd digital game, entertainment industry, mobile computing, participatory sensing, user experience.

\section{Introduction}

Brazil is the scene of a series of significant events such as Carnival, music festivals such as Rock in Rio, folk festivals, and sporting events. We can notice that the public of these events ceased to be just passive spectators and started to play an increasingly significant role (Edelman and Singer, 2015), mainly from the dissemination of technologies provided by smartphones. It is common to watch people use their smartphones to send text messages, interact on social networks, take pictures, film, and use flashlights (Bennett, 2012) while interacting during entertainment events. These devices provide a robust and little-explored computational tool. In this sense, Lordin (2017) seeks to answer questions related to the engagement of individuals during live events, concluding that individuals in the audience perceive the combination between the use of technology and interaction between artist and audience as something positive.

Designing this interaction requires knowledge of the audience's behavior at events. Especially in audiences classified as "mass event audiences" (Mackellar, 2013), one should consider the behavior of this mass and its possibilities for collaboration and interaction during the event. Each event has its characteristics related to the type of interaction expected and provided to the public, with the public itself being the protagonist in many of them. The dynamics of this event audience interaction can provide greater collaboration between members of the audience and, consequently, greater engagement of the audience with the event itself.

The Folkloric Festival of Parintins is an example of a mass audience event, where the audience is the protagonist of the show. In this event, there is a competition between two folkloric groups, the Boi Caprichoso and the Boi Garantido, who make their presentations, and a jury evaluates them following several criteria (Cavalcanti, 2000). One of the most relevant criteria, which consists of a tiebreaker item, is the participation of the fans. The audience not only acts as a spectator, but also directly influences the performance of the show. The rivalry between fans sets the tone for the show, and it is a vital feature of the culture of the State of Amazonas.

With the rivalry of Parintins Festival fans as a background, this paper presents research that aims to increase the collaboration between the participants in a competitive environment during events involving the festival's theme. It is sensible to use mobile computing technologies and crowd computing and sensing techniques in this context. Collaboration is encouraged through the Bumbometer, a collaborative and competitive game designed for crowds. Consequently, the research question raised in this paper is "In what extent has the Bumbometer app helped participants to feel engaged in rooting for their favorite folk group, along with other fans in the crowd?" . The interaction promoted by the game was explored in two case studies, the first in an actual crowd event during Carnival 2020 and the second in a small con- 
trolled event, taking place entirely remotely. The remainder of this paper is organized as follows. Section 2 presents the theoretical basis of the research and discusses some related works. Section 3 presents the research methodology and applied techniques. Section 4 describes the folkloric context of the research and details the development of the Bumbometer. In Section 5, the case studies carried out are presented, and the discussions are covered in Section 6. Finally, Section 7 presents the final considerations.

\section{Background}

To support the interaction, increase collaboration, and actively participate in entertainment events, it is necessary to understand the concepts related to the most different events and their respective audiences. Thus, this section describes a typology of events proposed by Getz (2007), and the different types of audience, as defined by Mackellar (2013). Besides, we address concepts of collaboration, cooperation, and competition. Finally, we present some related works involving the use of technologies in different types of events.

\subsection{Events and Audiences}

Getz (2007) studied and categorized events based on their characteristics with different perspectives to understand the different types of events. Knowing how to differentiate the types of events helps design specific technologies for interaction in a given event and reinforces knowledge from designing for different audiences. According to the author, there are eight main categories of events that are:

Cultural celebrations: events that provide joy and have some cultural significance for the region, which may include different types of events, but are separated from entertainment events due to their cultural character;

Recreational events: events commonly planned by parks, recreation agencies, non-profit organizations, churches, schools, or clubs. They have an unlimited number and scope, do not promote competitive activities, and comprise activities like running clubs, dance classes, and exercises or impromptu concerts;

Arts and entertainment events: popular events of the current generation of young people, including music concerts, award ceremonies, theater, art exhibitions, and dance shows;

Sports/competition events: this category involves events such as sports games, races, competitions, e-sport, tournaments, among others;

Business and trade events: comprise events such as markets, fairs, and farmers' exhibitions, where products are sold. World events such as fairs, exhibitions, cars or automobiles, promote international trade and, consequently, tourism;

Educational and scientific events: events for academic purposes, involving the creation and exchange of knowledge are part of this category. Academic and professional symposia, conferences related to specific topics are the main components of this category;

Private events: this category covers individual celebrations or demand for small groups, usually involving celebrations with themes that contain an emotional charge to par- ticipants, for example, weddings, birthday parties, funerals, theme parties, and church social events;

Political and state events: this involves events directly related to politics or produced by government entities, common examples are the G8 summit, the congress of political parties, protests, or visits by heads of state.

Different types of events aggregate different types of audiences. Its different objectives differentiate the public of each event. In Brazil, it is common to hold several festivals or festivals annually, such as Carnival, June party, or the Parintins Folk Festival. These are Cultural Celebrations events that explore the identity of the local people and their origins. These events take into account the local cultural issues of the audience. Usually, the public constantly seeks to get involved with the event by wearing clothes or other gadgets with the theme of the event.

Identifying the behaviors that emerge from the relationship of events and audiences helps to explore the particularities of different technologies, allowing to determine the most effective method of engagement. Mackellar (2013) presents a typology to classify the audience at events, and is based on the audience's objectives in attending the event. The typology is categorized into 5 different types, 'mass event audience', 'special interest audience', 'community audience', 'incidental audience', 'media audience'. Table 1 details each audience type.

Considering different perspectives of the audience in the context of events, crowds can identify these audiences' grouping that participates in the event. The classifications mentioned above represent how these audiences can group. Determine the type of behavior that the audience exercises, directly reflects the event's characteristics or determined by the internal policies of the place. For example, a typical event broadcasting on the internet or TV has an audience that follows it even through a screen, either using a smartphone or computer, limiting the interaction and communication between the public and the event.

In the Parintins Folk Festival context, the audience may be a mass, community, and media audience. In particular, an audience represents the local community that attends and participates in the event and seeks to disseminate the culture of the region. There is a mass audience with a general interest in attending the event, usually composed of tourists from other regions to attend the festival. The media audience follows the event through the broadcast of open TV from their homes or in pubs. All of these audiences represent different perspectives from the audience that accompanies the festival. It is essential to consider these perspectives to extract competitive and collaborative behaviors from the public so that the event can explore other forms of engagement.

\subsection{Competition, Cooperation, and Collabora- tion}

Collaboration and cooperation are essential activities and processes. Despite being similar, they are two very different and challenging concepts to grasp. Collaboration is the process by which people act together for a common goal, being a collective, synchronous activity that results from a sustained effort to build and maintain a shared understand- 
Table 1. Brief characterization of different types of audience. Source: Mackellar (2013).

\begin{tabular}{|c|c|c|}
\hline Type & Audience features & Event examples \\
\hline Mass audience & $\begin{array}{l}\text { - General interest in being entertained } \\
\text { - Social desire to be in a public space } \\
\text { - Expectation of entertainment } \\
\text { - Enjoyment of atmosphere of celebration } \\
\text { - May participate for religious reasons }\end{array}$ & $\begin{array}{l}\text { - City spectacular } \\
\text { - Oktoberfest } \\
\text { - Olympic Games } \\
\text { - Edinburgh International Festival } \\
\text { Hajj }\end{array}$ \\
\hline $\begin{array}{l}\text { Special interest } \\
\text { audience }\end{array}$ & $\begin{array}{l}\text { - Specialised recreational interest } \\
\text { - Links to other life interests } \\
\text { - Attendance at other similar events } \\
\text { - Expectation of specialist content } \\
\text { - Enjoyment of like-minded crowd }\end{array}$ & $\begin{array}{l}\text { - County flower show } \\
\text { - Birdfest } \\
\text { - National air show } \\
\text { - Fishing classic } \\
\text { - Dancing festival }\end{array}$ \\
\hline $\begin{array}{l}\text { Community } \\
\text { audience }\end{array}$ & $\begin{array}{l}\text { - Celebration of history or community feature } \\
\text { - Support for efforts of others } \\
\text { - Showcasing of local culture } \\
\text { - Participation in parades or dances, wearing of costumes } \\
\text { - Ceremonial traditions } \\
\text { - Raising funds for local charities }\end{array}$ & $\begin{array}{l}\text { - Reach Village Fair (UK) } \\
\text { - Grafton Jacaranda Festival (Australia) } \\
\text { - Sankofa Multicultural Festival (USA) } \\
\text { - Morden Corn and Apple Festival (USA) } \\
\text { - Kermesse (Belgium) } \\
\text { - Itel'men Tribal Harvest Festival } \\
\text { (Russia) }\end{array}$ \\
\hline $\begin{array}{l}\text { Incidental } \\
\text { audience }\end{array}$ & $\begin{array}{l}\text { - No pre-commitment to attend } \\
\text { - Attendance as part of seeking the culture of the destination } \\
\text { - No specific expectations } \\
\text { - Need for on-site information }\end{array}$ & $\begin{array}{l}\text { - Cultural festival } \\
\text { - City arts show } \\
\text { - Public sporting event }\end{array}$ \\
\hline Media audience & $\begin{array}{l}\text { - Worldwide access through media } \\
\text { - Enjoyment of close and personal experience } \\
\text { - Either passing or deep interest } \\
\text { - Mediated experience through the third party }\end{array}$ & $\begin{array}{l}\text { - British Open golf championship } \\
\text { - World Rally Championship } \\
\text { - Edinburgh Military Tattoo } \\
\text { - Olympic Games }\end{array}$ \\
\hline
\end{tabular}

ing of an issue or task. Cooperation otherwise denotes the act of delegating a more significant task to a group of people as an activity in which each person is responsible for a portion of the matter, not necessarily consistently collaborating. Competition occurs once two or more individuals strive for a common goal that cannot be shared: one's gain is the other's loss. Competition is the opposite of collaboration. It happens when individuals enjoy the challenge of achieving a better performance than others. Usually, individuals alternate between a competitive and a collaborative behavior (Szolnoki and Chen, 2021). However, in crowd games is not possible to have a team full of high performers individuals. Otherwise, in crowd games most of the involved individuals are not very competitive, what reduces the overall team performance (Preist et al., 2014).

Table 2. Aspects of collaboration vs cooperation in popular digital games.

\begin{tabular}{|l|l|l|}
\hline Game & Gameplay relations & Aspect \\
\hline Zombicide & $\begin{array}{l}\text { Players must cooperate in order to survive } \\
\text { until the end of the game, but not everyone } \\
\text { will win (Guillotine, 2012). }\end{array}$ & Cooperative \\
\hline Pandemic & $\begin{array}{l}\text { The game's central mechanic is coopera- } \\
\text { tive; the players are grouped into a team } \\
\text { that must work together in order for every- } \\
\text { one to win (Z-Man, 2008). }\end{array}$ & Cooperative \\
\hline $\begin{array}{l}\text { League of } \\
\text { Legends }\end{array}$ & $\begin{array}{l}\text { In an arena, two teams compete against } \\
\text { each other. Each player has a particular role } \\
\text { that varies depending on the team's strategy } \\
\text { (Riot, 2009). }\end{array}$ & Cooperative- \\
Competitive \\
\hline $\begin{array}{l}\text { Counter } \\
\text { Strike GO }\end{array}$ & $\begin{array}{l}\text { Two teams take turns arming and disarm- } \\
\text { ing a bomb. With limited movement space } \\
\text { and a faster pace of play, team communi- } \\
\text { cation becomes a critical factor in winning } \\
\text { the game (Valve, 2012). }\end{array}$ & $\begin{array}{l}\text { Cooperative- } \\
\text { Competitive }\end{array}$ \\
\hline Foldit & $\begin{array}{l}\text { The game's mechanics are based on the dis- } \\
\text { covery of protein forms, and the data col- } \\
\text { lected by players is used in science research } \\
\text { (Miller et al., 2020). }\end{array}$ & Collaborative \\
\hline $\begin{array}{l}\text { Pokémon } \\
\text { GO }\end{array}$ & $\begin{array}{l}\text { Players compete in individual battles } \\
\text { against the AI or other players in specific } \\
\text { locations called gyms. Each player is } \\
\text { assigned to a team, the overall score of the } \\
\text { team is used to determine the "owner" of } \\
\text { the gym (Niantic, 2016). }\end{array}$ & $\begin{array}{l}\text { Collaborative- } \\
\text { Competitive }\end{array}$ \\
\hline
\end{tabular}

A combination of these aspects is often beneficial to the player's experience in games. These elements are frequently used as the primary game mechanics, stimulating teamwork and providing players with a memorable experience. There are also electronic games with serious intent, such as Foldit, which allows players to contribute to scientific research by designing proteins (Kleffner et al., 2017). Other examples include the Pokémon Go mobile game, in which players from all over the world gather in specific locations and form leagues that compete against one another (Colley et al., 2017), as well as team-based games like League of Legends (Mora-Cantallops and Ãngel Sicilia, 2019) and Counter-Strike GO (Lux et al., 2019). Table 2 presents different aspects of those games regarding collaboration, cooperation and competition. The main interest in this work is to explore possibilities of interaction and audience immersion through technological digital games in live entertainment events, such as musical and cultural shows, which have been very little explored, in comparison with the digital game's industry. Figure 1 presents a graphic diagram with the three segments of interest in this work and the proposed collaborative-competitive crowd game, involving scientific research, digital game industry, and crowd entertainment events.

\subsection{Related Work}

Entertainment events are increasingly sophisticated, catering to diverse audience interests, being a prosperous and expanding industry. A consequence of the proliferation of events is the existence of several processes for developing interactive technologies with a focus on a wide diversity of audiences, including the public, even with no intention of interacting. The technologies resulting from these processes explore both the active spontaneity of the crowd and its possible implications and expand interactions already commonly present in some types of events (Vasconcelos et al., 2018).

In this perspective, interactive methods have grown significantly since the 1990 s in different contexts and differ- 


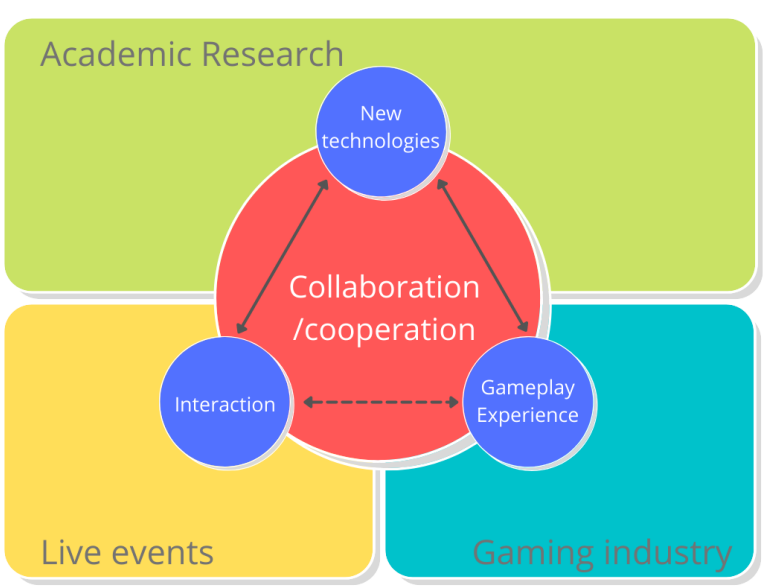

Figure 1. Synthesis of aspects of collaboration and cooperation, where besides academy and traditional game industry,

ent purposes, in particular educational events (Webster and Ho, 1997; Nelimarkka et al., 2016), various musical shows (Barkhuus and Jørgensen, 2008), sporting events (Veerasawmy and McCarthy, 2014), cultural festivals (Vasconcelos et al., 2018), among others. Among these events, some interesting works stand out, for example, in Veerasawmy and McCarthy (2014) when exploring uninhibited, emergent, and spontaneous aspects that arise during football matches.

Veerasawmy and McCarthy (2014) focus on sporting events and technologies used to increase the experience of the fans (crowd) through a prototype composed of an LED screen, microphone, and camera. Crowd characteristics such as noise or excitement movements are used to explore dynamics such as imitation, emergence, and self-organization. The technology Bannerbattle was developed as an alternative to exploring these aspects, inserting a kind of dispute between fans in football matches. The results of the case study conducted indicated that the previously defined qualities were well worked into the prototype. Furthermore, it was shown that the use of a game as a platform was quite efficient in engaging the audience in question Veerasawmy and Iversen (2012).

Consequently, the perception of interactive methods involving crowds and their impact on audience collaboration and active participation in events is constantly evolving, as in the aforementioned works and more recently in $\mathrm{Wu}$ et al. (2017) and Kayali et al. (2017). Despite this constant search for a broader interaction in favor of greater engagement, there are already consolidated methods in this context, such as bracelets equipped with LED lights (Burns, 2016). The innovation resulting from the application expands new forms of interactivity with audiences and artists, in addition to increasing the crowd's involvement with the event, thus promoting aspects of participation during the show.

In this sense, the number of publications in studies using applications or native functions of smartphones as an interaction method has increased, seeking to involve the crowd using applications for collaborative productions (Lee et al., 2019) or to expand participation in educational events such as lectures and conferences (Nelimarkka et al., 2016). It is important to notice that most of these methods involve music festivals or sporting events.

In this way, crowds are actively explored due to the ubiquitous presence of the smartphones of the public at events.
The use of this technology allows the exploration of innovative ways of interaction within the crowd, either individually or considering the crowd as a whole. For example, recently Jacucci et al. (2007) explored the idea that viewers don't go to events just to passively watch, and used "CoMedia", a mobile tool, integrated with information about the event and functions for sharing images among the list of friends at events. Another technology that turns the audience into active participants in events is "Graffito" (Sheridan et al., 2011). This technology increases crowd experience in events by providing a digital wall where the audience can interact drawing their graffite on it. The authors analyzed collaborative actions using measures of engagement in festivals.

These contributions have in common the objective of exploring different experiences based on crowds of different sizes, promoting opportunities for interaction, participation, and consequent engagement in different types of events mediated by technology. The importance of highlighting points in these technologies corresponds to knowing the extent to which the IHC has reached the perspective of interaction with the public, exploring the audience's experience, whether individually or collectively.

\section{Methods}

As mentioned in the previous Section, the Bumbometer App was originally developed to mimic a traditional competitive game called tug-of-war (or "cabo de guerra" in Portuguese). After changing the game's context and improving it to become the Bumbometer, we designed two case studies to test some hypotheses. We investigated crowd engagement in both case studies, using the Bumbometer app in slightly different contexts, namely: a natural event involving crowds, Carnaboi 2020, presented in Section 4.1; and, in a simulated scenario in a virtual event, with all participants geographically distant. This second case study scenario was fostered by the the raising context of social isolation, during COVID-19 pandemic's first phase in the first semester of 2020. Regarding categorization of The case studies, the first one is exploratory and it took place during a real face-to-face co-located event, just before the pandemic of COVID-19, and the second one is defined as explanatory because we already had some clues and hypothesis to check in an online scenario.

Face-to-face co-located events are characterized by public's disposition at the event, sense of collective engagement, influence that the venue adds to public's experience, presence of other people around and the sounds of the environment. All these aspects influence the engagement of the public in this type of events, changing the way people interact using Bumbometer app (Gomes et al., 2020).

In virtual events, these aspects are present in different ways, given that each user does not participate in the event physically, but follows the event through the Internet or TV. Many of the aforementioned aspects are not present virtually, such as the influence that the place adds to the experience, sense of collective engagement, and people around. These aspects of virtual events are limited by viewing on a screen and how the event is broadcast to users. Therefore, the experience is totally different, there is no proper atmosphere 
in the environment, impacting the UX during the use of the Bumbometer app.

For both case studies, we used engagement scales and interviews to find out people's level of engagement with and without the app, because as they are used to the competition and entertainment provided by these events, we assumed they started with some motivation level, even in the simulated online event.

The first case study took place during a large-scale event, planned for 20 thousand people: Carnaboi 2020. This exploratory case study aimed to evaluate whether there was observed engagement during interaction using the Bumbometer. It is worth mentioning that considering engagement is one of the main aspects of UX in the context of the evaluated application, two approaches were used to compare data in this case study. The first consisted of evaluating the $\operatorname{logs}$ generated by the application after each interaction round. The second used a scale technique for evaluating engagement, called User Engagement Scale (UES) (O’Brien et al., 2018).

The UES used is a reduced form of its original version proposed by O'Brien et al. (2018). The technique is based on a likert scale, where the participant indicates his agreement to a particular sentence, ranging from 1 to 5, being: 1 strongly disagree and 5 strongly agree. The UES consists of 12 sentences that assess four different dimensions, namely: (i) Focused Attention (FA), (ii) Perceived Usability, (iii) Aesthetic Appeal (AE) ), and (iv) Reward Factor (RW - Reward Factor). Each dimension is evaluated by 3 sentences.

The second case study was also for evaluating engagement using the Bumbometer but during a simulation of an online event, typical when it is not possible to gather crowds in a co-located space. In this explanatory case study, as we already had some clues and assumptions inherited from the previous case study, users' perception of the Bumbometer application was analyzed in two stages. In the first stage, the general UX of the application was evaluated using a scalebased technique, called AttrakDiff (Hassenzahl et al., 2003), which is the most used and known technique for evaluating UX in general (Pettersson et al., 2018). It was possible to use AttrakDiff more precisely because we had collected feelings, impressions, and opinions in the first study and wanted to be sure some of them do not change even when people are interacting online. In the second stage, we sought to analyze the specific aspects of engagement using the UES technique.

To corroborate with the chosen method for the explanatory case study, AttrakDiff is possibly one of the most wellknown UX assessment techniques (Brennand et al., 2019). It consists of 28-word pairs that evaluate pragmatic, hedonic, and attractiveness aspects. These word pairs are organized on a seven-point scale. The participant performs the UX assessment by marking the point closest to the adjective that best characterizes their user experience.

\section{Bumbometer: empowering the audience through a collaborative- competitive digital crowd game}

There is a rather particular type of event in Brazil: the folkloric festivals where the fans of each performance can help one of their preference collaboratively. However, in some of these festivals, there is stiff competition. Consequently, even though the nature of the event is collaborative, the competitiveness makes those events unique. Hence, we have a hybrid type of interaction. This section will characterize the types of interaction, give a brief introduction to the main events of this type, and present Bumbometer.

\subsection{Parintins Folklore Festival and the Carn- aBoi - Brazilian carnival derived event}

Parintins is an island city in the Amazonas state, located in the Northern Brazil. The city is world-renowned for the Parintins Folkloric Festival, recognized in 2018 as a Cultural Heritage of Brazil by the Brazilian National Historical and Artistic Heritage Institute (IPHAN). There are two folklore groups that dispute the Festival de Parintins, both based on a popular culture story about the death and resurrection of a farm ox, and which, therefore, have the ox as its main element. The tradition says that, once upon a time, a pregnant woman wanted to eat the tongue of an ox; to satisfy her, the husband kills the most beloved ox in the farm. The priest of the village is called and says that the population must organize parties and celebrate feasts which, if happy enough, will bring the animal back to life.

Festivities based on this story spread across the North and Northeast of Brazil, but in the city of Parintins it turned into a grandiose and creative spectacle that attracts thousands of people every year to the small island in the middle of the Amazon rainforest. The population is divided into two groups: the sympathizers of the "Boi Azul" (Blue Ox - a black ox with a blue star), called Caprichoso, and in the other side, the sympathizers of the "Boi Vermelho" (Red Ox - a white ox with a red heart), The official contest is held today during three nights in a stadium called "Bumbódromo", which fits about 35,000 people.

Given this scenario, some minor events derived from this famous Festival arisen. For example, in Manaus, capital of the State of Amazonas, during the traditional Brazilian Carnival festival, there is an event based on the Parintins Folklore Festival, where the main musical rhythm is the "Toada de Boi", and where important characters from the famous folk festival take place on a large stage, with the fans gathered in the same space as at a traditional music festival (Cavalcanti, 2000).

\subsection{The Game}

The Bumbometer app is a collaborative-competitive digital crowd game adapted to promote and measure the engagement of the fans of the two folklore groups, Garantido and Caprichoso, in events related to the Parintins Folklore Festival. Originally, the application emerged for a more general 
case of digital dispute between two groups, receiving the name of Cabo DIGuerra, in allusion to the playful game in which two teams pull at opposite ends of a rope until one drags the other over a central line, called Tug of War. The CaboDIGuerra app was developed in an undergraduate scientific initiation project, and it works by capturing data from multiple sensors of each individual's mobile phone device, who participates in the digital game by choosing one of two groups represented by different colors, to then accumulate the data captured from the two groups through a proper mathematical formulation. Then, the result is displayed on a screen with a bicolor graphic circle, half of each different color in the beginning, and which, as the dispute takes place, one color will take space until it completely dominates the circle (as if the cable had been all pulled to one side), with the due group winning the digital dispute. Motion capture (accelerometer) and audio sensors are applied.

However, the application version presented in this paper, called Bumbometer, arose from a technological partnership between the FunTechShow RD project of the Institute of Computing of the Federal University of Amazonas (IComp/UFAM), and the State Secretariat of Culture and Creative Economic of Amazonas (SEC-AM), promoting the CarnaBoi 2020 event. For this partnership, a prototype of the game was developed. The usability project and the humancomputer interface were further explored to promote a more significant user experience, which was then based on a Master's dissertation research. Both the undergraduate and Master's degree projects were part of the FunTechShow group, of intelligent digital entertainment, from IComp/UFAM.

As described in detail in a previous work of our research group (Martins et al., 2020a), the collaborative game has a client/server architecture consisting of two modules: the mobile client application and the web server application. In Figure 2 we show the mobile client module's screens. In Figure 3 we show some the server module's screens.

To play the game, the participants or players (the fans) must download the application on their smartphones, available on both Android and iOS platform Stores. Figure 2 presents the screenshots (A, B, C, and D) of the Bumbometer mobile app. In the Screen A, the participant must choose one of the two groups, Caprichoso or Garantido. In the Screen $B$ are presented the user manual, a step-by-step instructions to indicate how to use the mobile game. In the Screens C and $\mathrm{D}$ the mobile app shows the mobile game presents the screen relative to the chosen group in Screen A (a blue screen with the Caprichoso Ox or a red screen with the Garantido $\mathrm{Ox})$. So, when the game is started on the web server module, that is, when a session game is started, it will be on Screen $\mathrm{C}$ or $\mathrm{D}$, depends on the chosen group, that the game takes place in the client module, where participants must shake their smartphones and thus, send data from the motion sensor (accelerometer) to be accumulated on the web server, in the chosen group, during a given session of the game.

During a session of the game (a match), the smartphones' motion sensors capture twisting and shaking movements the player, and then, these acceleration data are sent, through the Internet, to a database where the web server application handles the collected data and then feeds the crowd intensity pointers, symbolizing which one is more excited at a given moment. The winning group (or team) in each comparison has its meter increased, as seen in Figure $3 \mathrm{~A}$. The one that reaches the top of the meter first wins, which causes a unique champion screen to appear (Figure $3 \mathrm{~B}$ and $\mathrm{C}$ ). In each game session we have a winner (which resulted from several comparisons that made the thermometer go up until one of the groups reached the top first, in a game session). For the event in question, each match had a maximum duration of thirty seconds, not to become tiring for the participants.

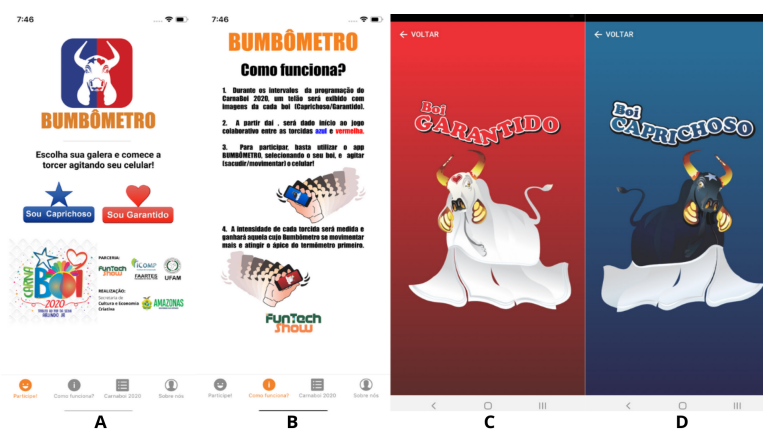

Figure 2. Screens of the Bumbometer app's mobile client module, available for both Android and iOS platforms.

The game was developed using the Ionic 4 framework, which is responsible for capturing the device's motion data in meters per second. This data is captured during 3 seconds, and then these values are averaged, which are sent via the Internet to a cloud database. The application Web was developed using the JavaScript language alongside CSS. It acquires data from Firebase, a cloud database chosen for being scalable and of low cost, and then processes the data, obtaining the acceleration values of all players. Each player is assigned a randomly generated ID for later data analysis. The visual representation of the competition data occurs through two vertical bars that act as intensity or temperature meters for the crowd (equivalent to thermometers). Figure 3, which moves according to the result of comparing the accumulated intensities of the group of fans of each folkloric group, this being the sum of the values of each team. This measurement takes place every one second.

People move their mobile devices as they participate in the contest by jumping and dancing. This movement generates several files of log sent to the application Web and containing data collected during the execution of the matches. A log example of Bumbometer app can be seen in Figure 4. Among these data, there are:

a) start and end date and time of each match.

b) the number of connected customers measured every second.

c) acceleration data for each device, using the ID assigned to it, at each instant when the comparison of values is performed.

As for the classification of aspects of the Bumbometer, described in Table 3, it can be labeled as a collaborative and competitive game at the same time.

On the one hand, as seen in Table 3, the Bumbometer has a cooperative bias because the goal is to win together, with each fan cooperating individually through their smartphone. On the other hand, the participation or non-participation of 

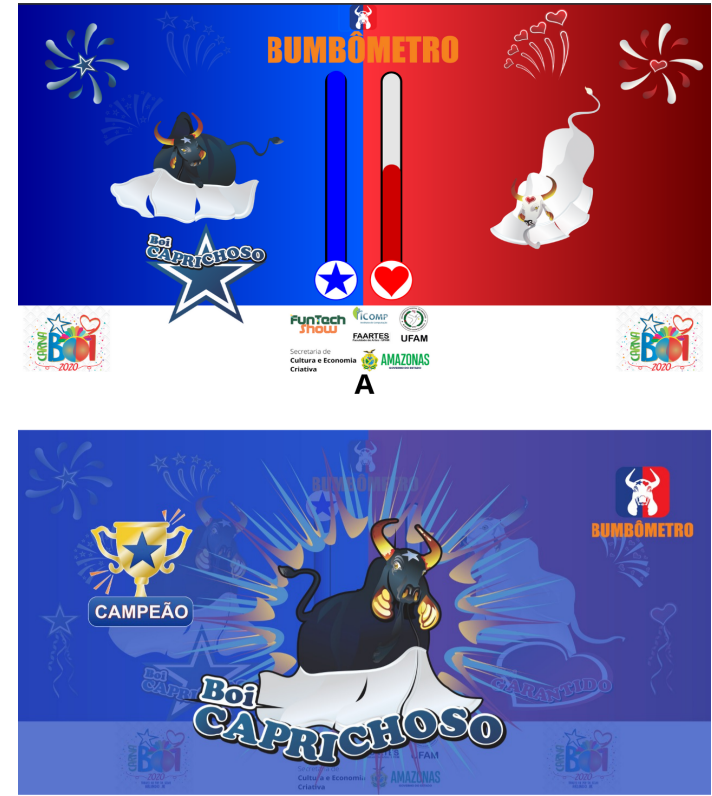

B

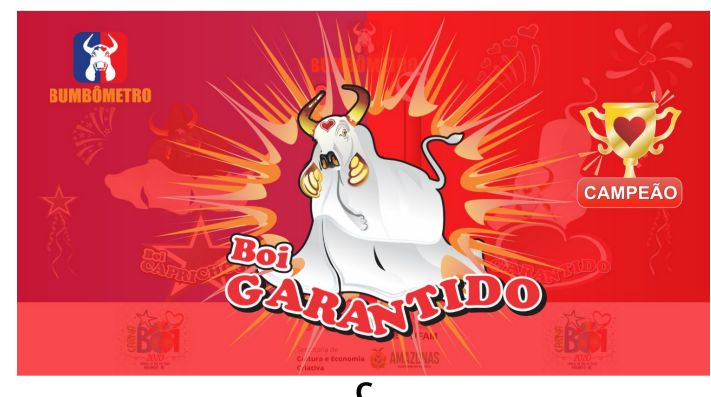

C

Figure 3. Web server module screens, where (A) each team has a thermometer that moves according to the data captured by the set of the mobile, and (B) and (C) the winner screen that appears at the end of each session of the game (a match), for Caprichoso and Garantido, respectively.

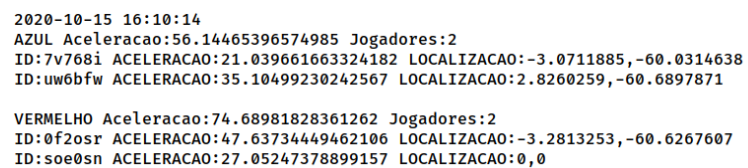

Figure 4. Example of log generated by the Bumbometer application.

a player does not directly interfere with the individual experience of the others, who can play in the same way. Therefore, the game is better classified if presented as collaborative since this term has a broader meaning, encompassing cooperation and involving other characteristics.

The Bumbometer is also a competitive game. It results in a shared victory or defeats so that the competition between the two teams is visible and is part of the game's mechanics.

However, despite Table 3 considering only the patterns of participation-action of collaboration and competition, there is also the possibility of the player's omission in specific situations, as in the case where he enters the game and finds it boring, feels tired of the mechanics of the game (movement of shaking the cell phone) or when there is simply a change of focus of the player, who may prefer to film the event instead of playing, for example.

In the next section, the proposed case studies are presented, the methodology applied to conduct the experiments, as well as the results of the game application, are discussed.
Table 3. Summary table of aspects that characterize the Bumbometer app.

\begin{tabular}{|c|c|c|}
\hline \multicolumn{3}{|c|}{ Bumbometer } \\
\hline \multirow{2}{*}{$\begin{array}{c}\text { Aspect } \\
\text { of the Game }\end{array}$} & \multicolumn{2}{|c|}{ Perception Patterns - action } \\
\hline & Collaboration & Competition \\
\hline Vision & \multicolumn{2}{|c|}{ Possible for everyone } \\
\hline Motivation & Passion & Hatred \\
\hline Objective & Win together & Win the other \\
\hline The other & $\begin{array}{l}\text { Partner, } \\
\text { friend }\end{array}$ & $\begin{array}{l}\text { Adversary, } \\
\text { enemy }\end{array}$ \\
\hline Relationship & $\begin{array}{l}\text { Interdependence } \\
\text { and Partnership }\end{array}$ & $\begin{array}{l}\text { Dependency } \\
\text { and Rivalry }\end{array}$ \\
\hline Feelings & Joy / ecstasy & Anger / frustration \\
\hline Symbol & Bridge & Obstacle \\
\hline Action & Play With & Play Against \\
\hline Climate & Excitement & Rivalry \\
\hline Results & \multicolumn{2}{|c|}{$\begin{array}{l}\text { Shared victory } \\
\text { Shared defeat }\end{array}$} \\
\hline Consequence & $\begin{array}{c}\text { Willingness } \\
\text { to keep playing }\end{array}$ & $\begin{array}{l}\text { Finish the first } \\
\text { game }\end{array}$ \\
\hline
\end{tabular}

\section{Case Studies}

In this section, the two proposed case studies are described: one involving a real, large-scale event, with a multitude of participants located in person at the event; and another, a small, completely virtual controlled event. The results are reported and discussed next, according to the methodology and techniques described in the previous section.

\subsection{Interaction in real world crowd event be- fore the COVID-19 pandemic: Carnaboi 2020}

As previously mentioned, Carnaboi is an annual event that takes place during the carnival season in the city of Manaus, inserting the folk tradition of the Parintins Festival in the carnival revelry.

In 2020, Carnaboi happened in February, shortly before the confirmation of the first case of COVID-19 in Brazil ${ }^{1}$, and the organization pointed to the use of different technologies for public engagement during the event, such as the creation of hashtags for use on social networks and posting photos of the public on the screens during the event. This more technological scenario made it possible to use the Bumbometer application as a tool for audience interaction and engagement.

\subsubsection{Preparation}

Introducing new forms of audience engagement at an event with the characteristics of Carnaboi requires careful planning. Therefore, numerous meetings were held in association with the Secretariat of Culture and Creative Economy of Amazonas (SEC-AM) to facilitate the use of the Bumbometer application during the event. Definitions of moments of interaction, a form of feedback to the user, and an incentive to use the application were necessary.

\footnotetext{
${ }^{1}$ https://agenciabrasil.ebc.com.br/en/saude/noticia/2020-02/brazilconfirms-first-case-coronavirus
} 
Days before the event, there was a comprehensive meeting with organizers, artists, and those responsible for technical matters such as lighting and sound. On that occasion, the Bumbometer was presented to everyone through a demonstration. It was defined, together with the artists, that the application would be used in the intervals between presentations during the event. The artists were able to install the Bumbometer and use it during the demonstration so that they could get to know the application and spread it among their fans through social networks.

Another aspect point when designing an action involving applications from mobile devices concerns the early disclosure of the application. The audience must arrive at the event with the application installed. To this end, advertising pieces were broadcasted on SEC-AM and artists' social media, in addition to the event's commercials on open TV.

As feedback media for the audience, the event would feature LED screens on the sides of the stage, where thermometers would be displayed for each crowd. In addition, advertisements for the app would be displayed on horizontal " banner" style screens, inspiring the spectators to install the Bumbometer on their devices.

The application requires an active connection to the internet to send data from the sensors of the devices to calculate the agitation of the fans. Hence, it was decided that an open Wi-Fi network would be made available to all event participants. Therefore, access to the internet was guaranteed regardless of the user's internet availability. A link was provided to make it possible to install the application for those who had not previously installed it.

\subsubsection{Execution}

As defined in the planning meetings, advertisements for the application were displayed on the screens, inviting the audience present to install on their devices. The presenter of the event announced the moments when the application should be used. At that time, he invited fans from both teams (oxen) to turn on the app, select their team and interact by shaking the device. The visual feedback with the thermometers indicating the crowd's agitation was displayed on the screens on the sides of the stage.

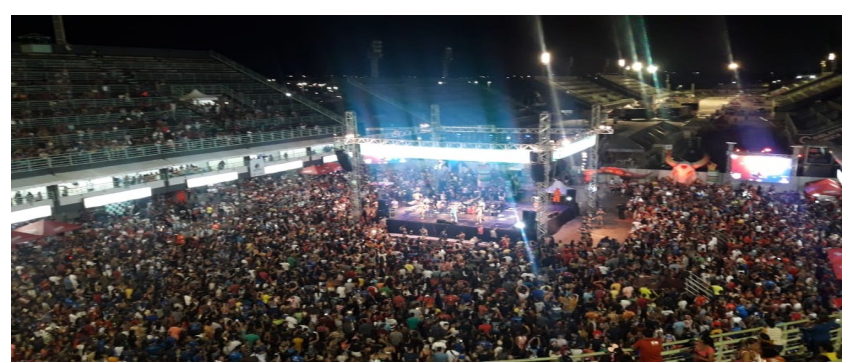

Figure 5. Image of the Carnaboi 2020 event. Source: Portal Beiju.

At each interval between stage shows, the presenter of the event invited the audience to participate in an interaction section that represented an engagement dispute with the Bumbometer. The fans of the teams reacted with the shaking of the devices, screams, and jumps. Each section lasted $30 \mathrm{sec}-$ onds. In all, 5 sections were held, all pulled and encouraged by the presenter of the event. Due to heavy rain, other sections of interaction were impracticable, as the screens had to be turned off and people sought shelter.

Figure 5 illustrates the event where the Bumbometer was used. It is possible to observe the horizontal screens in the form of a banner above the stage and at the bottom, on the right side of the figure, one of the screens is observed where the feedback of the interaction was given to the participants.

After the rounds, some members of the audience of the event were approached and invited to answer a questionnaire with the UES technique to assess their engagement. Among the people approached, six participants agreed to answer the questions. At a time after the event, the application logs, as well as the activity logs of the app stores, were analyzed.

It is worth mentioning that the interaction in this specific event needs to be provoked because rivalry is a characteristic among the fans. For this, an effect of $80 \%$ is expected in a more controlled environment, such as the Parintins Folk Festival, since this is an additional resource for the fans. In other events, such as Carnaboi and lives in general (and the simulated live presented in this article), in which there was no real dispute, the engagement objective was 30\% in Carnaboi, without a pre-established goal, because it was a simulation for future achievement. To have a more reliable approach, the way in which this interaction occurred at the Carnaboi event can be verified from the 12th minute of the video available on the Internet: https : / www . facebook. com/watch/live/ $? \mathrm{v}=2294362407530458 \&$ \&ef $=$ watch_permalink.

\subsubsection{Results}

Throughout the audience interaction with the Bumbometer application, logs were generated. These logs contain the following information: departure, date, time, participant identification, participant team, and values of the participant's device motion sensor (accelerometer). Such information was analyzed as evidence of people's engagement during the moments of interaction with the application.

During the event, there were 5 games (interaction rounds). Table 4 shows the number of people who interacted on each team for each of the matches. The total number of participants and the winning team in each of the matches is also displayed. It is worth mentioning that the winning team did not necessarily consist of the team with the most participants, but rather the team that was most excited and that shook the device with more intensity, that is, the one that had the greatest accelerometer vibration.

Table 4. Interaction round table during Carnaboi 2020

\begin{tabular}{|c|r|r|r|l|}
\hline ROUND & $\begin{array}{l}\text { QTY } \\
\text { BLUE }\end{array}$ & $\begin{array}{r}\text { QTY } \\
\text { RED }\end{array}$ & TOTAL & WINNER \\
\hline 1 & 100 & 35 & 135 & GARANTIDO \\
\hline 2 & 32 & 26 & 58 & GARANTIDO \\
\hline 3 & 40 & 26 & 66 & GARANTIDO \\
\hline 4 & 504 & 396 & 900 & CAPRICHOSO \\
\hline 5 & 154 & 182 & 336 & GARANTIDO \\
\hline
\end{tabular}

The higher the values of the accelerometer, the greater the intensity of the shaking of the device, a fact that indicates a greater engagement during the interaction round (departure). 
Figure 6 illustrates the average values of the teams' sensors at each moment during the 5 interaction rounds (matches). It is possible to notice the predominance in the interactions of the participants of the red team that won 4 of the 5 disputed rounds. The average values of the accelerometer sensor of the participants of the red team were higher than those of the blue team, although fewer people were participating.

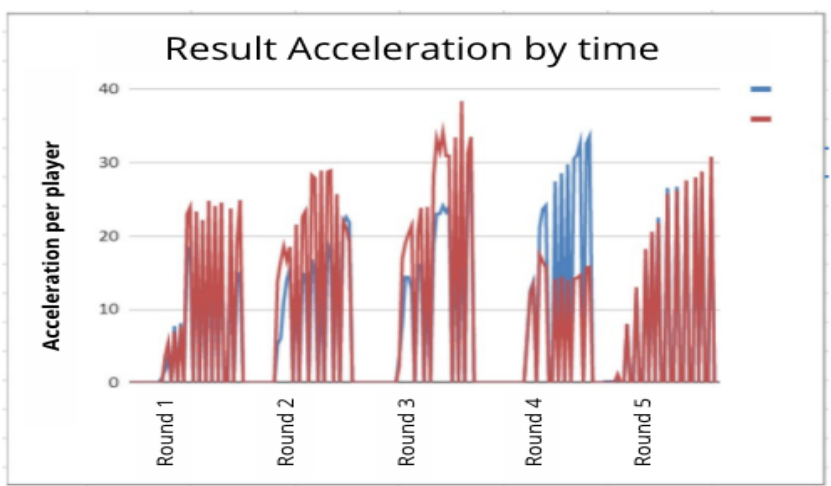

Figure 6. the average acceleration of the teams during the 5 interaction rounds at Carnaboi

Figures 7 and 8 shows the number of installs of the application from the App Store and Play Store application stores, respectively. Figure 7, referring to installations on iOS system devices, shows two very evident installation peaks. The first concerns the day after the presentation of the demonstration of the Bumbometer to the artists of Carnaboi 2020. The second peak consists of the day of the event itself. Figure 8, referring to installations on Android devices shows an increasing curve where the peak is precisely on the day of the event and the next day. Considering that the event took place on the 24th at night, the installations after midnight are counted on the 25 th. Thus, it is clear that even with advertisements on social media and television, people were interested in installing the application only during the event, when perceiving the interaction provided.

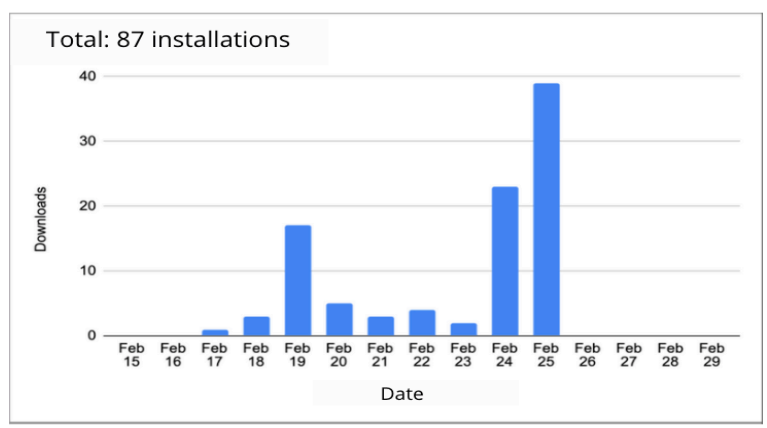

Figure 7. Installations chart on IOS devices

\subsubsection{Evaluation of engagement with UES - Results}

Considering that engagement is a fundamental factor of UX to the application context, this factor was assessed during the event using the UES technique, as described in Section 3. The evaluation of engagement with UES (O'Brien et al., 2018) included 6 respondent participants who were approached during the event and agreed to participate in the study. The difficulty in recruiting participants for the study is because the

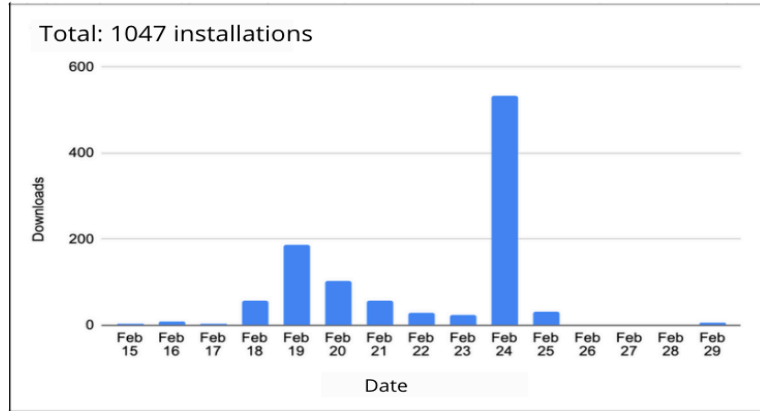

Figure 8. Installations chart on Android devices

study environment was not controlled and, because it is a real event, the participants were there to entertain themselves and not participate in a traditional UX assessment. The results of the evaluation can be seen in Figure 9.

\begin{tabular}{|c|l|c|}
\hline Sentence & Dimension & Dimension Average \\
\hline I lost myself in this experience. & Focused Attention & \\
\hline The time I spent using the App just slipped away. & Focused Attention & \multirow{2}{*}{3,1} \\
\hline I was absorbed in this experience. & Focused Attention & \\
\hline I felt frustrated while using this App & Perceived Usability & \\
\hline I found this App confusing to use. & Perceived Usability & \multirow{2}{*}{1,6} \\
\hline Using this App was taxing. & Perceived Usability & \\
\hline This App was attractive. & Aesthetic Appeal & \multirow{2}{*}{4,2} \\
\hline This App was aesthetically appealing. & Aesthetic Appeal & \multirow{2}{*}{4,7} \\
\hline This App appealed to my senses. & Aesthetic Appeal & \\
\hline Using App was worthwhile. & Reward Factor & \\
\hline My experience was rewarding. & Reward Factor & \multirow{2}{*}{4,7} \\
\hline I felt interested in this experience. & Reward Factor & \\
\hline
\end{tabular}

Figure 9. UES Results - Interaction at Carnaboi 2020

When looking at Figure 9, it is possible to notice that only the dimension related to usability was evaluated as a very low grade. This result further reinforces the usability aspects of the application, showing the need for an adaptation to provide a more pleasant, pleasurable use experience and consequently improving perceived UX. However, it is noted that these problems did not affect the engagement of the participants, who evaluated the other dimensions as positive, showing that the experience was worthwhile. This shows that the Bumbometer app serves well the purpose for which it was developed, but that some aspects of usability can be improved so that the application provides an even better UX and consequently can enable a greater engagement of the participants during the experience.

\subsection{Quarantine interaction}

The COVID-19 pandemic caused people to adhere to social isolation to prevent the rapid spread of the new coronavirus. As a result, events such as concerts and parties were canceled as an action to avoid crowds of people. In this new scenario, as a way of relieving and entertaining people, several artists started to make live presentations transmitted over the Internet, from their own homes. Such presentations became popular under the name of "lives ". Thus, the entertainment industry had to adapt to the new times and formats taking greater advantage of digital information and communication technologies.

This context proved to be conducive to the exploration of the Bumbômetro application/game, since the requirements for its operation would be: large public and availability of Internet access. Lives have attracted more and more people and, to watch them, it is necessary to connect to the network. 
Thus, to investigate engagement through the Bumbometer in a virtual event, a pilot case study was carried out in a simulation of a virtual event in a controlled environment. The goal was to explore usability and UX on the Bumbometer at remote events for crowds.

The event participants were invited and interested in investigating different ways of interacting in a remote environment. In the pilot case study with the Bumbometer, participants were asked to evaluate the application's UX, considering its use in a broader context, by the crowd, separated by social isolation. The meeting was scheduled in the Google Meet tool so that it was possible to observe the reaction of everyone watching the live.

\subsubsection{Preparation}

To make the use of the Bumbometer feasible, everyone should previously install it on their devices. Therefore, a link to the app stores for Android and iOS devices was sent to participants via email two days before the synchronous meeting. To collect the responses of the participants regarding the application's UX, forms were created using Google Forms with the questionnaires of the AttrakDiff and UES techniques. The evaluation using the first technique aimed to evaluate in general the UX of the Bumbometer. The second technique sought to analyze, more specifically, aspects of engagement in this scenario of a virtual event.

\subsubsection{Execution}

Thirty-five participants and three researchers attended the online meeting for the pilot case study, one of them acting as a presenter of the "live" event. During a previous explanation by one of the creators of the game, the participants were introduced to this application. It was shown the context for which it was developed and to prospect its large-scale use remotely, in a real event. Then the participants were invited to insert themselves in a moment of interaction where they should put themselves in the place of spectators of a "live" where the attractions belonged to opposite teams and they would be encouraged to interact. Each one was free to choose one of the teams and the interaction, commanded by one of the creators of the Bumbometer, started. The feedback of the interaction, which consists of thermometers, was shared with everyone (Figure 10).

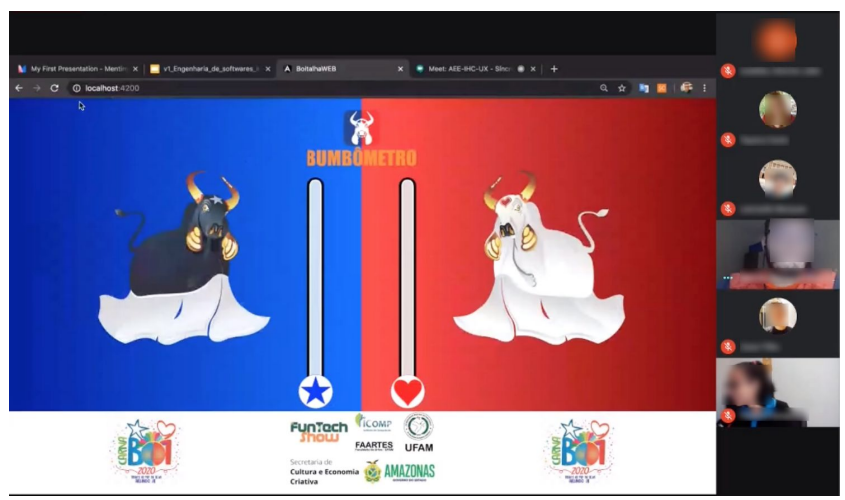

Figure 10. Feedback screen of online interaction using the Bumbometer.

Two rounds of interaction were carried out. The first is for participants to understand the idea of the app and how it works. The second is for them to have one more experience of use. Each round a different team won. The participants were then able to have feedback on the victory of both teams. It is worth mentioning that each participant was free to change teams between one round and another if they wanted to. Figure 11 illustrates one of the moments of interaction with the Bumbometer.

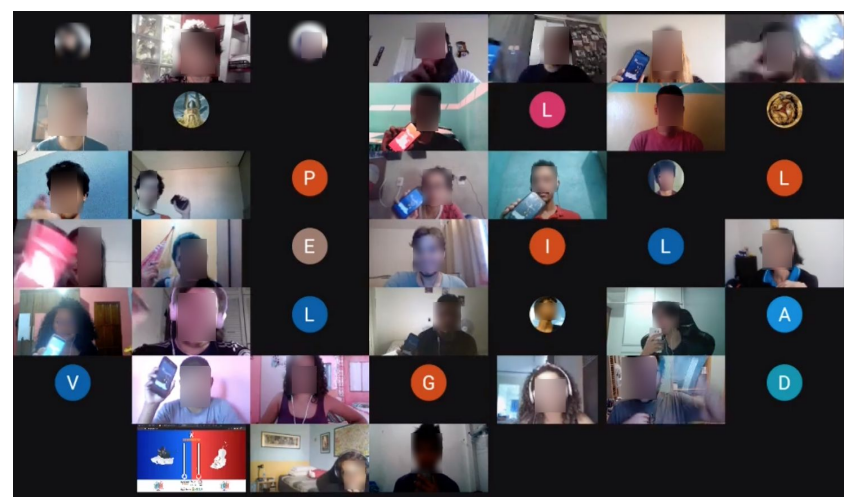

Figure 11. Students participating in the study when interacting with the Bumbometer.

After the two rounds of the interaction of the Bumbometer, the participants were invited to complete the questionnaires related to the AttrakDiff and UES techniques, as mentioned. The average response time was 10 minutes to complete both questionnaires. The results are analyzed below.

\subsubsection{Results}

AttrakDiff evaluates UX in terms of pragmatic, hedonic aspects, and attractiveness. The results of AttrakDiff will be presented through Figure 12, where it is possible to see the percentage of how the participants marked a certain item of the technique. The colors in Figure 12 vary according to the points on the scale, where a more negative rating is indicated by the colors in reddish tones, while a more positive rating is indicated by the colors in greenish tones. When a participant replied "neutral", that is, he did not consider the aspect measured by the negative or positive item, the color represented in the figure is gray.

When looking at Figure 12, the interest is in analyzing which aspects were considered most positive or negative according to the participants. Concerning the negative aspects, they can be easily visualized by looking at the pairs of words that have the highest indexes of negative evaluation, that is, the pairs in which the shades of red are more evident. It is possible to verify that five pairs of words stand out negatively $(6,7,8,11$, and 25). These pairs are, respectively, professional / non-professional, ugly / attractive, practical / non-practical, stylish / tacky and undemanding / challenging.

These aspects were perceived negatively by the study participants, which indicates that they are aspects that need to be improved in the application so that it can provide a better UX to these aspects. Looking at the word pairs, you can see that the participants would probably like the interface to be more professional and attractive. As they were people who know HCI concepts, perhaps they were analyzing only the aesthetic factor in these items, a statement reinforced by the 


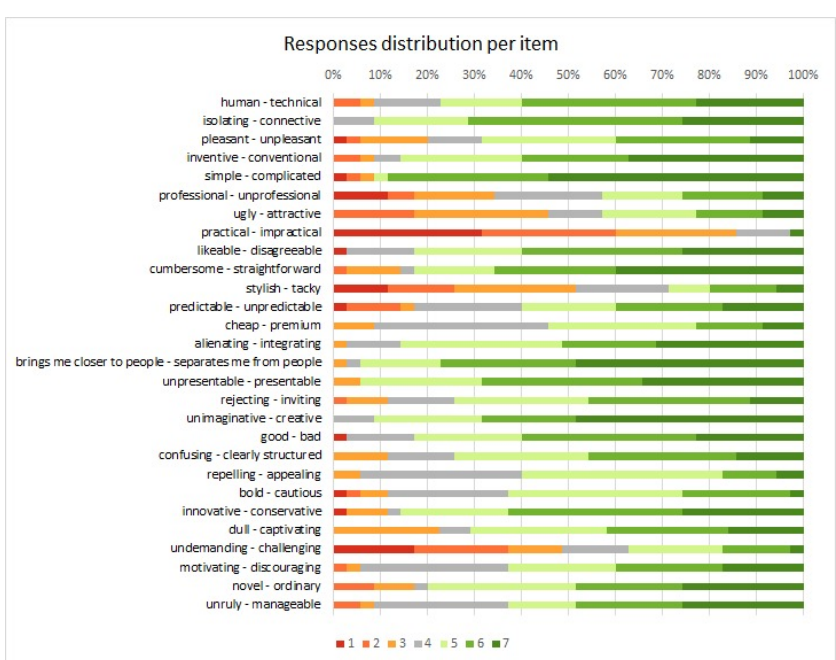

Figure 12. AttrakDiff Results - Remote Virtual Interaction.

analysis of the choice for more positive words in other pairs. The non-practical item deserves more attention because it is not contrasted with a positive element. Participants noted that it could be tiring to wiggle the mobile device all the time. The assessment as challenging was due to the lack of feedback, which was easily corrected.

On the other hand, it is observed in Figure 12 that, in general, the participants had a more positive perception due to the predominance of positive evaluations (indicated by the color green). The isolating/connective, simple/complicated, ambiguous/clear word pairs stand out, bring me closer to people/move me away from people, without imagination/creative and innovative/conservative (pairs 2, 5, $10,15,18$, and 23, respectively). Considering the innovative nature of the application, users needed to have this perception when using and evaluating it. The results showed that the participants consider the application innovative, creative, connective, which helps to bring people closer together, all of which are extremely important characteristics in the context of the application. Also, it was perceived as clear and simple, that is, the participants were able to easily understand the purpose of the application. These results show that the application meets the main objectives for which it was developed, requiring only a few interface adjustments to provide an even more positive user experience.

In addition to the general perception of the application, it was important to verify engagement as a fundamental aspect of UX concerning the context of the application. Therefore, a specific evaluation was carried out using the UES technique (O'Brien et al., 2018). The results of this assessment can be found in Figure 13.

\begin{tabular}{|c|l|l|}
\hline \multicolumn{1}{|c|}{ Sentence } & Dimension & \multirow{2}{*}{ Dimension Average } \\
\hline I lost myself in this experience. & Focused Attention & \multirow{2}{*}{2,6} \\
\hline The time I spent using the App just slipped away. & Focused Attention & \multirow{2}{*}{2,4} \\
\hline I was absorbed in this experience. & Focused Attention & \\
\hline I felt frustrated while using this App & Perceived Usability & \\
\hline I found this App confusing to use. & Perceived Usability & \multirow{2}{*}{3,0} \\
\hline Using this App was taxing. & Perceived Usability & \\
\hline This App was attractive. & Aesthetic Appeal & \multirow{2}{*}{3,0} \\
\hline This App was aesthetically appealing. & Aesthetic Appeal & \multirow{2}{*}{3,6} \\
\hline This App appealed to my senses. & Aesthetic Appeal & \\
\hline Using App was worthwhile. & Reward Factor & \multirow{2}{*}{} \\
\hline My experience was rewarding. & Reward Factor & \multirow{2}{*}{} \\
\hline I felt interested in this experience. & Reward Factor & \\
\hline
\end{tabular}

Figure 13. UES Results - Remote Interaction

When looking at Figure 13, it is possible to verify that the two dimensions with the lowest overall scores (average) were FA and PU. Regarding the FA dimension, it appears that the participants did not pay so much attention to the experience that they were immersed in. However, this can be explained by the low grade of the PU dimension, related to the perceived usability of the game. By not being perceived positively concerning its usability, the participants may have focused more on understanding how to use the app/game itself and getting to know it than effectively immersing themselves in the experience. These results reinforce the results obtained through AttrakDiff, where the participants indicated that an improvement is needed in aspects related to the application's ease of use and feedback.

On the other hand, the AE and RW dimensions scored more positively, indicating that the participants found the app attractive and at the same time that the experience was worthwhile, attracting the interest of the participants. The fact that the application is aesthetically attractive does not conflict with the ease of use of the interface, since its design may have been pleasant, but the layout of the features may have made interaction difficult. Also, the sentences present in these two dimensions show that users had a positive engagement during the experience, motivated by the possibility of remote interaction and by the collaborative and competitive characteristics of the activity and the game.

\section{Discussion}

The Bumbometer game's design aims to enhance audience interaction during an entertainment event where there is a strong appeal for a healthy competition between two teams. Although its interface is clean and straightforward, the game has a consistent process of acquiring and managing data, and it also requires a crowd dynamic for planning its usage.

Analyzing both case studies as one unity towards the use of a game to support interaction in a competitive and collaborative way, we confronted logs, UX methods, and direct observation to evaluate engagement and participation using the Bumbometer App. It is worth mentioning that the original plan was to conduct both case studies in face-to-face settings. However, with the pandemic context that followed the first one, during Carnaboi, we reached out a secondary research question about the impact of a remote setting in audience's engagement.

Table 5. Comparative table between the Bumbometer and other crowdsourcing applications.

\begin{tabular}{|l|l|l|l|l|l|}
\hline Features & Bumbometer & BannerBattle & Open Symphony & Graffito & CoMedia \\
\hline $\begin{array}{l}\text { Audience } \\
\text { mode }\end{array}$ & Onsite/remote & Onsite & Onsite/remote & Onsite/remote & Onsite/remote \\
\hline Internet needs & Yes & No & Yes & Yes & Yes \\
\hline $\begin{array}{l}\text { Operational } \\
\text { or network } \\
\text { infrastructure }\end{array}$ & No & Yes & No & No & No \\
\hline $\begin{array}{l}\text { Need for indi- } \\
\text { vidual use de- } \\
\text { vice }\end{array}$ & Yes & No & Yes & Yes & Yes \\
\hline $\begin{array}{l}\text { Kind of inter- } \\
\text { action }\end{array}$ & $\begin{array}{l}\text { Online real- } \\
\text { time }\end{array}$ & Real-time & Online real-time & $\begin{array}{l}\text { Online real- } \\
\text { time }\end{array}$ & Online \\
\hline $\begin{array}{l}\text { Participants } \\
\text { number }\end{array}$ & 2-Crowd & 2-Crowd & $\begin{array}{l}\text { Performers and } \\
\text { crowd }\end{array}$ & Crowd & Crowd \\
\hline $\begin{array}{l}\text { Organizational } \\
\text { cost involved }\end{array}$ & Low & High & Low & Low & Low \\
\hline $\begin{array}{l}\text { Participant } \\
\text { cost involved }\end{array}$ & $\begin{array}{l}\text { Requires a } \\
\text { mobile device }\end{array}$ & Null & $\begin{array}{l}\text { Requires a device } \\
\text { with browser }\end{array}$ & $\begin{array}{l}\text { Requires a a } \\
\text { mobile device }\end{array}$ & $\begin{array}{l}\text { Requires abile device } \\
\text { mober }\end{array}$ \\
\hline Aspect & $\begin{array}{l}\text { Cooperative- } \\
\text { Competitive }\end{array}$ & $\begin{array}{l}\text { Cooperative- } \\
\text { Competitive }\end{array}$ & Cooperative & Cooperative & Null \\
\hline
\end{tabular}


As seen in Table 5, our work differs from other crowdsensing applications by having a competitive aspect as an interaction stimulant. Papers such as Open Symphony (Wu et al., 2017) and Graffito (Sheridan et al., 2011) uses purely cooperative interactions, by which they seek to engage the users. CoMedia (Jacucci et al., 2007) specifically works as a kind of social media and consequently does not possess a gameplay aspect to compare to. However, their study case indicated that they succeeded in engaging the event audience by being a part of the event and not just an addon. BannerBattle meanwhile uses a classic team-based approach, by which the authors tried to engage two crowds in a battle, which resulted in a high level of participation of the public. However, their approach required the installation of dedicated infrastructure and did not allow participation from spectators not onsite. The Bumbometer integrated the positive findings of those experiences by incorporating a team-based approach, having a cooperative and competitive aspect, allowing both onsite and remote participation, being low cost, and by being integrated into the event itself while a part of it since the beginning.

As mentioned in Section 3, the Bumbometer's game design considers the context of a traditional folkloric festival called "Boi Bumbá" and its related events, such as the "Carnaboi." Due to these events' competitive characteristics, the Bumbometer game adopts a crowd dynamic which privileges competition but keeping cooperation a goal among team members, who may also reach collaboration when combining different strategies for achieving high results in their bull's thermometer. Remarkably, some hybrid interaction elements in entertainment events are unique for the events described in the case studies. It is worth mentioning that there is an urge for audience participation in both cases by their nature. Because there is a natural opposition between the bulls, people are willing to lead their team to win.

Even with the audience's willingness to engage, whether they keep engaged depends mainly on the immediate feedback and their perception of feeling they play an important role as their team's supporters. This feeling raises collaboration because the technological game works as a standalone app, and the crowd dynamic starts with a presenter, who keeps giving feedback when showing the thermometers. Results in the case studies point out collaboration was a shared goal within teams. Even though people engage in the fostered interaction, according to Carnaboi's analysis, usability was affected, mainly because people do not feel comfortable holding their mobile device and shake it unnaturally for their preferred bull to win. Confronting usability issues pointed out with engagement measures, we conclude that it had no impact on the overall enjoyment. The probable cause for engagement being unaffected is the short duration of each match. During the second study, participants remained seated in front of their cameras in a simulated event, and they did not point out any usability issues. In that case, the recommendation for short matches is essential for keeping usability issues diminished for the Bumbometer game and other interactive applications in other entertainment events.

Another consideration is audience attention, which does not deviate from artists' performances. This focus on performance impacted the initial match when only a few people in
Carnaboi and a Simulated live audience engage. The presenter needed to show their low interaction results to urge them to engage in the next match. From this second match, the audience started to negotiate different ways to shake their device to win, acting out collaboratively and, at the same time, competing against their opposite bull's supporters. Competitiveness between supporters' teams is essential for creating a constructive hybrid interaction with no personal animosity. In both case studies, this productive hybrid interaction took place. However, during the simulated online event, people felt they need to engage more effectively, and the Bumbometer made it possible for them to feel more immersed in the experience.

Besides the benefits Bumbometer brought to both scenarios, simulated live and Carnaboi, it is worth arising an important argument during a pandemic situation. The simulated live results point out, related to the UX perspective, participants (audience) had a positive experience, diminishing the feeling of distance unavoidable by the event's virtual nature. It is clear when analyzing the results from AttrakDiff, referring to the pair "it joins me to people / it separates me to people." Participants'positive perception of this element shows that their overall experience provided them a sense of participation and proximity, even at a physical distance. Furthermore, making people feel close to one another during social distancing times is a challenge and a benefit if achieved to mitigate the lack of face-to-face activities. In this way, the virtual event described in the second case study brings to light the possibility of entertainment.

To sum up results, after the aforementioned considerations, regarding the primary research question posed in Introduction "In what extent Bumbometer app helped participants to feel engaged in their teams?" have a positive answer. In both case studies the Bumbometer app helped audience to feel engaged, even for those participants who played with less intensity. As the setting for the second case study deviated from its original goal, the secondary research question raised about the impact of a remote setting in audience's engagement, results showed that the audience enjoyed having a more active role even in remote events.

Finally, specifically regarding the second case study, interaction during a simulated live show, it fleshes out the importance of more research in the context of interaction, collaboration, and cooperation in virtual entertainment events. Moreover, it shows that proposals like the Bumbometer, aiming at engaging people in productive interaction during a virtual entertainment event, may bring new ways of interaction. In this direction, the design of new interaction paradigms comes as a necessary step forward in discussing interaction foundations, raising the need for new ways to evaluate the quality of that interaction. Towards issues for different evaluation methods, there is the work of Marques et al. (2020) which investigates the creation of UX metrics for logs of entertainment events apps, aiming at giving more meaning to the data collected during the app usage to identify clues of people's experience. 


\section{Concluding Remarks}

The proposal of hybrid interaction for entertainment events, which contains the participation of rival fans, was the focus of this article. The Bumbometer is a competitive game when considering the two fans, but collaborative if the interaction between the pairs of the same crowd is considered.

Of the various types of entertainment events that involve opposing sides, the chosen case was the context of the Parintins Folk Festival, the interfaces being customized to meet the characteristics of the dispute between the two oxen, Caprichoso and Garantido. To refine the application as a whole and the visible part in the form of a game, two studies were carried out. The first was in a live face-to-face event while the second was in a simulated virtual event with the participation of people through an online meeting environment. The objective of this second was to verify the virtual engagement, its possible losses, and/or advantages concerning face-to-face events.

The results of the studies, in both evaluation methods used, point to a high engagement in entertainment events with the competition. Therefore, the hybrid interaction is extended with the use of a game like the Bumbometer, as long as it does not occur during the entire event, but at moments stimulated by who is conducting it, in this case, a presenter.

As future work, we intend to investigate deeply the use of the Bumbometer in more virtual events and with more people participating at the same time. In the face of a pandemic context, research on virtual entertainment tends to grow as interest in these events becomes more evident. In this sense, it is important to produce empirical evidence on how to provide this type of entertainment by producing a good experience for people.

\section{Acknowledgements}

This article consists of a revised and expanded version of the paper entitled "Enhanced interaction: audience engagement in entertainment events through the Bumbometer app" presented during the XIX Brazilian Symposium on Human Factors in Computer Systems (IHC 2020) and published in the proceedings of the conference (Martins et al., 2020b).

We are grateful for the support provided by the Amazonas State Secretariat for Culture and Creative Economy (SEC-AM). This research was also supported by the Institutional Program for Scientific Initiation Scholarships 20182019 of the National Council for Scientific and Technological Development (PIBIC CNPq), the Brazilian federal government agency under the Ministry of Education (CAPES) - Finance Code 001, and FAPEAM through Publication 003/2019 POSGRAD UFAM Edition 2019. And, as provided for in Art. 48 of Decree No. 6.008 / 2006. This research, according to Article 48 of Decree $n^{\circ} 6.008 / 2006$, was partially funded by Samsung Electronics of Amazonia Ltda, under the terms of Federal Law $n^{\circ} 8.387 / 1991$, through agreement $n^{\circ} 003 / 2019$, signed with ICOMP/UFAM.

\section{References}

Barkhuus, L. and Jørgensen, T. (2008). Engaging the crowd: studies of audience-performer interaction. In $\mathrm{CHI} 08$ ex- tended abstracts on Human factors in computing systems, pages 2925-2930. ACM.

Bennett, L. (2012). Patterns of listening through social media: online fan engagement with the live music experience. Social Semiotics, 22(5):545-557.

Brennand, C. V. L. T., Brennand, C. A. R. L., Duarte, E. F., and Baranauskas, M. C. C. (2019). Evaluating the user experience in interactive installations: A case study. In Proceedings of the 18th Brazilian Symposium on Human Factors in Computing Systems, IHC '19.

Burns, L. A. (2016). The concept album as visual—sonictextual spectacle: The transmedial storyworld of coldplay’s mylo xyloto. IASPM@journal,6(2):91-116.

Cavalcanti, M. L. V. d. C. (2000). O boi-bumbá de parintins, amazonas: breve história e etnografia da festa. História, ciências, saude-Manguinhos, 6:1019-1046.

Colley, A., Thebault-Spieker, J., Lin, A. Y., Degraen, D., Fischman, B., Häkkilä, J., Kuehl, K., Nisi, V., Nunes, N. J., Wenig, N., Wenig, D., Hecht, B., and Schöning, J. (2017). The geography of pokémon go: Beneficial and problematic effects on places and movement. In Proceedings of the 2017 CHI Conference on Human Factors in Computing Systems, CHI '17, page 1179-1192, New York, NY, USA. Association for Computing Machinery.

Edelman, D. C. and Singer, M. (2015). Competing on customer journeys. Harvard Business Review, 93(11):88100.

Getz, D. (2007). Event studies: Theory, research and policy for planned events. Elsevier Butterworth-Heinemann.

Gomes, G., de Freitas, R., Castro, T., and Gadelha, B. (2020). Interaheu: heuristics for technological interaction on events. In Proceedings of the 19th Brazilian Symposium on Human Factors in Computing Systems, pages 16.

Guillotine (2012). Zombicide - a zombie havoc boardgame by guillotine games. https://www.zmangames.com/ en/games/pandemic/. Accessed: 2021-04-15.

Hassenzahl, M., Burmester, M., and Koller, F. (2003). Attrakdiff: Ein fragebogen zur messung wahrgenommener hedonischer und pragmatischer qualität. In Mensch \& computer 2003, pages 187-196. Springer.

Jacucci, G., Oulasvirta, A., Ilmonen, T., Evans, J., and Salovaara, A. (2007). Comedia: mobile group media for active spectatorship. In Proceedings of the SIGCHI Conference on Human Factors in Computing Systems, pages 1273 1282.

Kayali, F., Hödl, O., Fitzpatrick, G., Purgathofer, P., Filipp, A., Mateus-Berr, R., Kühn, U., Wagensommerer, T., Kretz, J., and Kirchmayr, S. (2017). Playful technologymediated audience participation in a live music event. In Extended Abstracts Publication of the Annual Symposium on Computer-Human Interaction in Play, pages 437-443. ACM.

Kleffner, R., Flatten, J., Leaver-Fay, A., Baker, D., Siegel, J. B., Khatib, F., and Cooper, S. (2017). Foldit standalone: a video game-derived protein structure manipulation interface using rosetta. Bioinformatics, 33(17):2765-2767.

Lee, S. W., Willette, A., Koutra, D., and Lasecki, W. S. (2019). The effect of social interaction on facilitating au- 
dience participation in a live music performance. In Proceedings of the 2019 on Creativity and Cognition, pages 108-120. ACM.

Lordin, D. (2017). Consumer engagement during concerts : A study on using mobile interactive technology to enhance the live music event experience. Master's thesis, KTH, School of Computer Science and Communication (CSC).

Lux, M., Halvorsen, P., Dang-Nguyen, D.-T., Stensland, H., Kesavulu, M., Potthast, M., and Riegler, M. (2019). Summarizing e-sports matches and tournaments: The example of counter-strike: Global offensive. In Proceedings of the 11th ACM Workshop on Immersive Mixed and Virtual Environment Systems, MMVE '19, page 13-18, New York, NY, USA. Association for Computing Machinery.

Mackellar, J. (2013). Event Audiences and Expectations. Routledge advances in event research series. Routledge.

Marques, L., Amazonas, M., Castro, T., Assuncao, W., Zaina, L., Gadelha, B., and Conte, T. (2020). Ux trek: a postinteraction journey from immersive experience logs. In Proceedings of the 19th Brazilian Symposium on Human Factors in Computing Systems, pages 1-6.

Martins, G., de Freitas, R., and Gadelha, B. (2020a). A mobile game based on participatory sensing with real-time client-server architecture for large entertainment events. In 2020 XLVI Latin American Computing Conference (CLEI), pages 332-339. IEEE.

Martins, G., Gomes, G., Conceição, J. L., Marques, L., Silva, D. d., Castro, T., Gadelha, B., and de Freitas, R. (2020b). Enhanced interaction: Audience engagement in entertainment events through the bumbometer app. In Proceedings of the 19th Brazilian Symposium on Human Factors in Computing Systems, IHC '20, New York, NY, USA. Association for Computing Machinery.

Miller, J. A., Khatib, F., Hammond, H., Cooper, S., and Horowitz, S. (2020). Introducing foldit education mode. Nature Structural \& Molecular Biology, 27(9):769-770.

Mora-Cantallops, M. and Ãngel Sicilia, M. (2019). Team efficiency and network structure: The case of professional league of legends. Social Networks, 58:105-115.

Nelimarkka, M., Kuikkaniemi, K., Salovaara, A., and Jacucci, G. (2016). Live participation: augmenting events with audience-performer interaction systems. In Proceedings of the 2016 ACM conference on designing interactive systems, pages 509-520.

Niantic, I. (2016). Pokémon go. https : //pokemongolive. com/pt_br/. Accessed: 2021-04-15.

O'Brien, H. L., Cairns, P., and Hall, M. (2018). A practical approach to measuring user engagement with the refined user engagement scale (ues) and new ues short form. International Journal of Human-Computer Studies, 112:28-39.

Pettersson, I., Lachner, F., Frison, A.-K., Riener, A., and Butz, A. (2018). A bermuda triangle? a review of method application and triangulation in user experience evaluation. In Proceedings of the $2018 \mathrm{CHI}$ Conference on $\mathrm{Hu}$ man Factors in Computing Systems, pages 1-16.

Preist, C., Massung, E., and Coyle, D. (2014). Competing or aiming to be average? normification as a means of engaging digital volunteers. In Proceedings of the 17th ACM conference on Computer supported cooperative work \& social computing, pages 1222-1233.

Riot (2009). League of legends. https://na. leagueoflegends.com/en-us/. Accessed: 2021-0415.

Sheridan, J., Bryan-Kinns, N., Reeves, S., Marshall, J., and Lane, G. (2011). Graffito: crowd-based performative interaction at festivals. In CHI'11 Extended Abstracts on Human Factors in Computing Systems, pages 1129-1134. ACM.

Szolnoki, A. and Chen, X. (2021). Cooperation and competition between pair and multi-player social games in spatial populations. Scientific Reports, 11(1):1-9.

Valve (2012). Counter strike go. https://store. steampowered.com/app/730/CounterStrike Global_Offensive/. Accessed: 2021-04-15.

Vasconcelos, V., Amazonas, M., Castro, T., Freitas, R., and Gadelha, B. (2018). Watch or immerse?: Redefining your role in big shows. In Proceedings of the 17th Brazilian Symposium on Human Factors in Computing Systems, page 41. ACM.

Veerasawmy, R. and Iversen, O. S. (2012). Bannerbattle: introducing crowd experience to interaction design. In Proceedings of the 7th Nordic Conference on Human-Computer Interaction: Making sense through design, pages 228-237. ACM.

Veerasawmy, R. and McCarthy, J. (2014). When noise becomes voice: designing interactive technology for crowd experiences through imitation and invention. Personal and ubiquitous computing, 18(7):1601-1615.

Webster, J. and Ho, H. (1997). Audience engagement in multimedia presentations. ACM SIGMIS Database: the DATABASE for Advances in Information Systems, 28(2):63-77.

Wu, Y., Zhang, L., Bryan-Kinns, N., and Barthet, M. (2017). Open symphony: Creative participation for audiences of live music performances. IEEE MultiMedia, 24(1):48-62.

Z-Man (2008). Pandemic board game. https://www . zmangames.com/en/games/pandemic/. Accessed: 2021-04-15. 